Corresponding Author:

Martina Giusti

martina.giusti@unifi.it

Received: 17 November 2019

Accepted: 6 January 2019

Published: 12 January 2020

Publishing services provided by

Knowledge

(c) Martina Giusti et al. This article is distributed under the terms of the Creative Commons

Attribution License, which

permits unrestricted use and

redistribution provided that the

original author and source are credited.

Selection and Peer-review under the responsibility of the EBEEC Conference Committee.

\section{Planning and Managing of Diagnostic Imaging Technologies in Healthcare: The Introduction of Managed Equipment Service (MES) for the System's Sustainability}

\section{Martina Giusti ${ }^{1}$, Niccolò Persiani ${ }^{2}$, Fissi Silvia ${ }^{2}$, and Renzo Ricci ${ }^{3}$}

${ }^{1}$ Department of Experimental and Clinical Medicine, University of Florence, Florence, Italy

${ }^{2}$ Department of Economics and Management, University of Florence, Florence, Italy

${ }^{3}$ Local Health Authority Toscana Centro, Florence, Italy

\section{Abstract}

The lack of resources has driven healthcare management studies to recognise Private and Public Partnerships (PPP) as the solution in managing efficiency, effectiveness and profitability of technological innovation. Recent researchers have identified the buying model called Managed Equipment Service (MES), in which purchaser and seller share the risks of technology's management and use, as an optimal problem-solving method. The aim of this research is to analyse the potential economic financial and organisational benefits of MES introduction in healthcare, in particular for the acquisition of the diagnostic imaging technologies.

The research applies the case study method. We have examined a representative Italian Local Health Authority for its dimensions, managerial characteristics and case mix offered but, especially, for its high health standards. In the study we have involved the strategic figure of radiographer in diagnostic imaging.

The data has been elaborated through statistical analysis to observe the correlations. Evidence demonstrates that MES costs are lower than all the other planning and purchasing methods analysed (between 11\% - 239\%). When correlations between age of facilities and effectiveness of provided services is strong, MES grants the maintenance of a lower average age of technologies and a more efficient use of resources and significant margins of profitability.

The emerging model of PPP is a possible solution to the current issues surrounding economic and financial sustainability of healthcare systems, considered the fewer resources and the technological progress. MES in healthcare appears to be a highly efficient way of managing innovation, in particular for diagnostic imaging technologies.

Keywords: Public Private Partnership (PPP), Managed Equipment Service (MES), middle-high technologies, diagnostic imaging.

Jel classification codes: 110, g31, h41. 


\section{Introduction}

The idea of exchange the traditional purchase methods of health equipment (property) with newer models of leasing, based on complex financial approaches such as outsourcing [1], promotes an international argument of discussion about its corporate and legal declination.

The reason for the attention on new forms of integration between producer and user of technologies is due to two fundamental reasons. The first is the few resources availabled to the national health systems, particularly for investments and for capital grants [2]; this condition induces Local and National Health Authorities to look for a collaboration with the suppliers, which can guarantee the availability of machines and sustainable modalities of financing to purchase technologies with scarce budgets [3]. The situation results are also aggravated by a second problem: the demonstrated inability of a lot of Health Authorities and Hospitals to manage adequately the system of investments' plans, which doesn't provide the requirements of technological equipment's renewal considering the obsolescence and the continuous innovation of technology $[4 ; 5 ; 6]$.

The analyse of investment plans of Health Authorities and Hospitals shows that they often contain a list of 'wishes' coming from physicians instead of a real instrument for capital budgeting. There operate only on three-year so they aren't strategic levers of the middle -- long period. The requests of goods in surplus is wrongly transposed, while the replacement of obsolete machineries or the management of the technological upgrade are left out.

This inefficiency, which is common in all developed countries and emergent in the developing nations, inevitably involves more costs of maintenance, useless machines stops for failures, reduced use of equipment and too long waiting lists for fundamental exams for patient's health [7].

In Anglo-Saxon countries, the subscription of Public-Private Partnership (PPP) and the modalities of technology supply in leasing, are an effective solution to these problems [8; 9; 10]. They are also integrated with multiple services of programming and advising.

In particular, Managed Equipment Service (MES) is a new contractual approach in the acquisition of medical devices of medium-high technology [11], including also the ancillary services for their use, which is taking place in the European panorama following the advent of Public-Private Partnership (PPP). This contractual form expects the supply of the complete service, which constantly guarantees the availability of a performed fleet of machines over a long period, against a pre-established annual fee and the allocation 
of the incurred expenditure to income statement instead of the balance sheet, making the maintenance of the economic balance of hospitals easier.

Therefore, MES emerges like a model for the complete management of technological equipment in the middle-long term, which gives the supply of health equipment, its renewal, its installation, its test, its maintenance, its performance's monitoring and its upgrade, process governance and staff attention to the customer [12].

With this contract the hospitals and health authorities share with the supplier the risks of physic and technological obsolescence of the possessed goods but also knowhow and abilities. The supplier should be seen as a partner in the management of equipment and not as the counterpart.

Nowadays MES is interesting seen as a possible solution to increase the services' quality and performance of the healthcare structures from both the theoretical and professional viewpoint.

Therefore, the aims of this paper are:

- to define a more efficient modality to plan investments and to deepen the opportunities offered from new instruments of health technologies supply, particularly analysing the Managed Equipment Services (MES),

- to elaborate a methodology of comparison between the results obtained both new model and traditional methods, developing and elaborating a rational approach, which can really compare the different opportunities offered by the market.

The research analyses the investments' plans for diagnostic imaging technologies of middle-high complexity to assess both economic and management relevance.

We individuate the Department of Complex Technologies in the Local Health Authority as a case study.

After the study of the current state of the considered equipment, a set of tools is developed with the collaboration of a radiographer, which allows to compare the incurred costs for investment plans with a hypothetical MES,

Finally, the disbursements envisaged by the business investment plans, MES fee and deprecation are compared and conclusions are drawn. 


\section{Method}

The research group tries to understand, if MES is more advantageous than the investment plans' methodology used in European Local Health Authorities and Hospitals.

This project is developed in Italy given the high performance standards of National Health System, its universal public service feature available to every citizen and the present regulatory constraints.

The case study method $[13 ; 14]$ was considered the optimal modality for the present work. The Local Health Authority of Teramo, in Abruzzo, for three specific reasons:

1) it holds together 4 hospitals and a settled territorial network;

2 ) it is programming the realisation of a new hospital, which centralises most of its services. In particular, the study is conducted analysing selected diagnostic imaging middle-high technologies of the Department of Complex Technologies;

3) it has a structured and acknowledged analytical accounting by participation to national network, which guarantees the high quality of collected data about its economic and managed actions.

This study is divided into three phases.

The first phase involves the collection of data on a selected diagnostic imaging equipment of medium-high technology (4 Mammographs, 8 Ultrasound machines, 13 X-Ray devices, 2 Magnetic Resonance Imaging and 5 Computer Tomography), which was located in the considered Department in 2015. 2015 was chosen as reference year because data was not available to complete the documentation for 2016 , when the research started. Accordingly, data was set as if it was observed in 2016. Data were collected from the analysis of budgets and investment plans from 2013 to 2018. Quantitative indicators (average age of fleet, machine stops, degree of technologies' use) were processed and evaluated based on accredited benchmarks by the scientific community [15], in order to identify critical points and virtuosities.

The second phase involves the development of a standardised investment plan, which integrates the critical issues detected by the analysis of actual business investment plans. The standardised plan seeks to remove the subjective variables considered for the development of investment plans, starting from the analysis of quality level of the available technologies in terms of innovation, updating and efficiency in comparison with national and international standards [16; 17]. The standardised investment plan is the link between the current method of investments' plans and MES. It was developed thanks to the collaboration of the radiographer. The programming of purchases in healthcare is usually delegated to experts in the economic-financial sector or engineers of HTA so that 
activity is completely detached from the operational process. A possible solution to this problem to the creation of a multidisciplinary team, which includes health professionals engaged in the working practice, as technicians, nurses, etc. This integration increases the knowledge of the instruments, their adaptability and utility. In the specific case, radiographers must be involved in investment plans realisation because they are how the purchased instruments will be user friendly, used in respect of the achievement of budget objectives, comfortable for patient, etc; thus, the investment plan will be more functional to the real needs of the department of diagnostic imaging, as a fundamental tool for the organisation of the service.

In the final phase, the MES fee is calculated for a ten-year contract (2016-2025), which provides for the supply of the same machine number selected at the quantity and technological level. This is useful to evaluate the potential benefits that the signing of an MES gives compared to a common investment planning method. The disbursements envisaged for each considered planning method are compared over a four-year period (2016-2019). The costs related to the investment plans realised to the Local Health Authority (2016-2018 and 2017-2019 disbursements) are compared with the standardised plan (elaborated in this study), the amount due in four years of the MES contract and with the supported depreciation of the analysed machinery by health realities.

Finally, conclusions will be drawn based on the results obtained, and possible uses and developments of the project carried out will be identified.

\section{Analysis of the Installed Technological Equipment}

In the full equipment of the Department of Complex Technologies in the Local Health Authority of Teramo were been selected only the facilities, of which is complete the process from their planning of purchase to their use: 4 Mammographs (MRX), 8 Ultrasound machines (Echo), 13 X-Ray devices (RX), 2 Magnetic Resonance Imaging (MPRI) and 5 Computer Tomography (CT).

All the machines were acquired through ownership (out of 32 technologies observed only $1 \mathrm{CT}$ is leased). For each technology the following parameters were been analysed because they were considered significant for their impact on the obtainable performance:

- the average age of the equipment;

- the number of machine stops; 
- the degree of use of technologies.

With the analysis of the average age of the equipment (fig. 1), we intended to verify the ability of the current adopted planning system to keep the technologies in good working and to guarantee their timely replacement. Then, the average age of the different types of machine was compared with the useful life, estimated by Assobiomedica (Following the mission of Assobiomedica: “'Assobiomedica [...] promotes the cultural, social and economic value of innovation, research and technological development, contributing to the enhancement of the Italian National Health Service".Watched on March 18, 2019 at the link: https://www.assobiomedica.it/it/chi-siamo/mission/index.html,), the most important Italian association of manufacturers of biomedical and diagnostic technologies. Data show how most of the technologies have surpassed, sometimes so much, the expected useful life. With the exception of the recently renovated CT, all technologies are close or have already exceeded the identified cut-off value. The consequences of this situation are risks of the daily activity for the obsolescence of the available machines.

To understand the effects of this inefficiency, the number of machine downtimes was collected in 2015 and in 2016 (fig. 2). This situation equates to lost revenues quantified at $€ 311,182.00$ in 2015 and $€ 395,923.00$ in 2016; it seems evident that greater efficiency in the management of this parameter could guarantee, with its savings, the financing of some of the needed renewals. It was due to the only unplanned downtime of the chosen technologies.

Finally, the degree of use of the specific technologies is verified trough the analysis of the daily activity for each machine (fig. 3). It was intended to investigate the intensity with which the machines are actually used to produce the services and to identify its real production's capacity. The use of the equipment appears limited; indeed, the analysis shows the commissioning of certain machines for only half a day. The direct consequences of this underuse are waiting lists beyond the range of acceptability (sixty days for the first appointment available) and failure to meet the budget targets set.

The reasons for this situation can be ascribed to the difficulties of programming, which have emerged in several steps of the analysis, and to the lack of staff able to deal with it.

Moreover, the budget constraints strongly limit long-term choices, impose buffer solutions, with the highlighted consequences, and block the renewal of the installed machines. This situation is the opposite of the wished in a Local Health Authority, which is engaged in the realisation of the new unique hospital garrison since it would allow the optimisation of its functionality. 


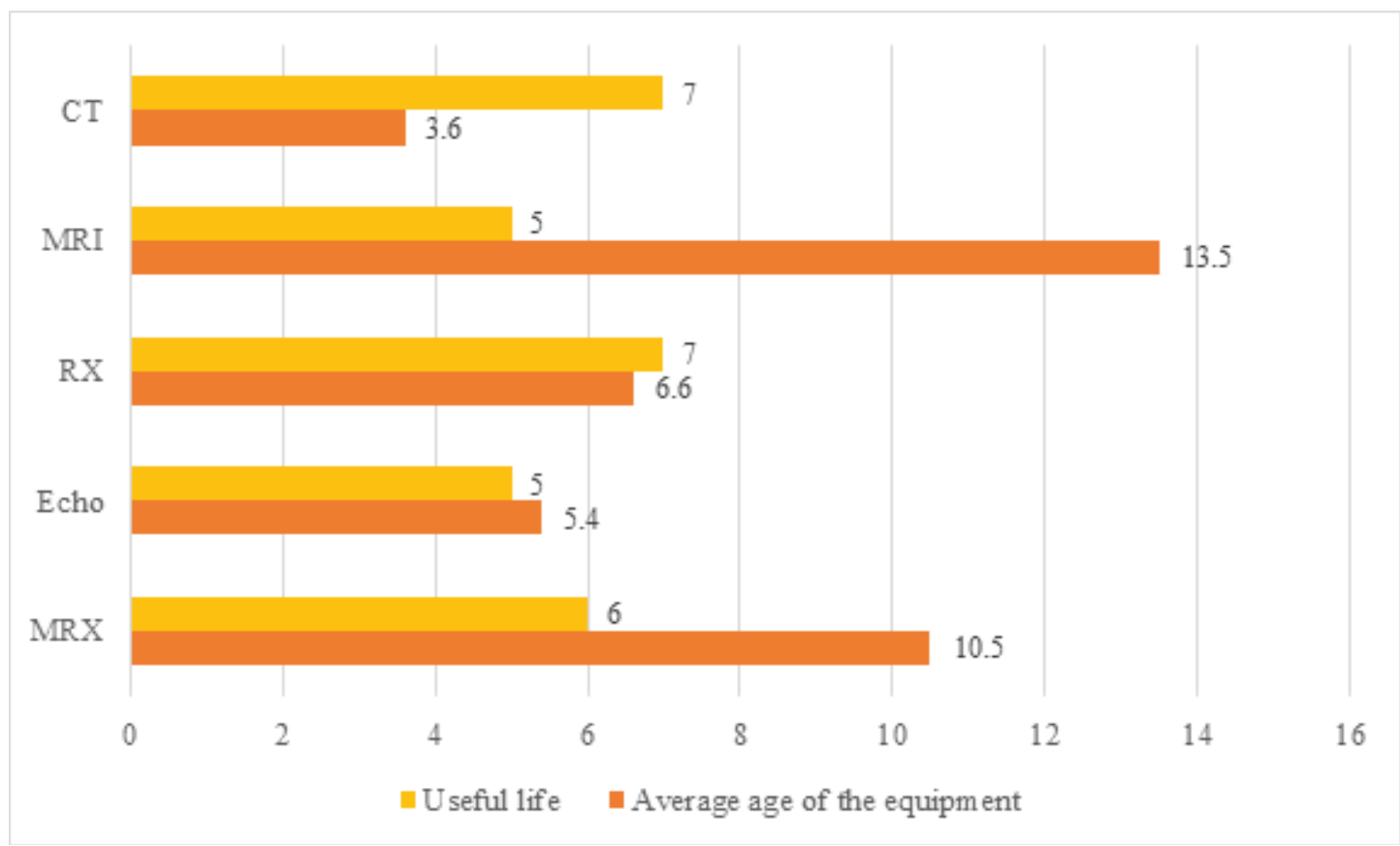

Figure 1: Average age of the equipment and useful life (years).

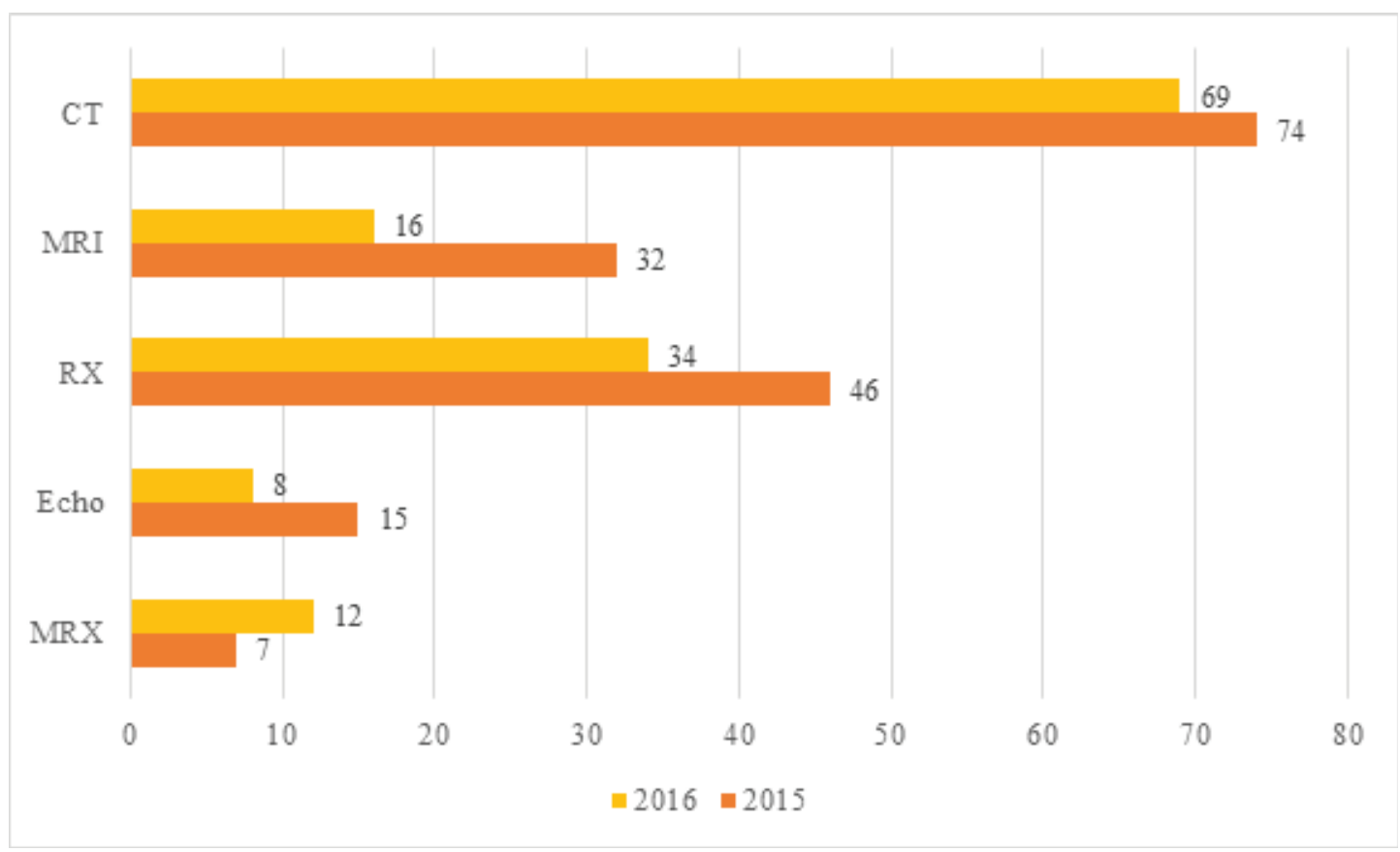

Figure 2: Machine's stops.

Given the situation described, an investment planning method like MES has appeared as a valid and possible solution to provide an adequate response. Indeed, MES allows the management of the structures and staff working concomitantly with the provision of services. 


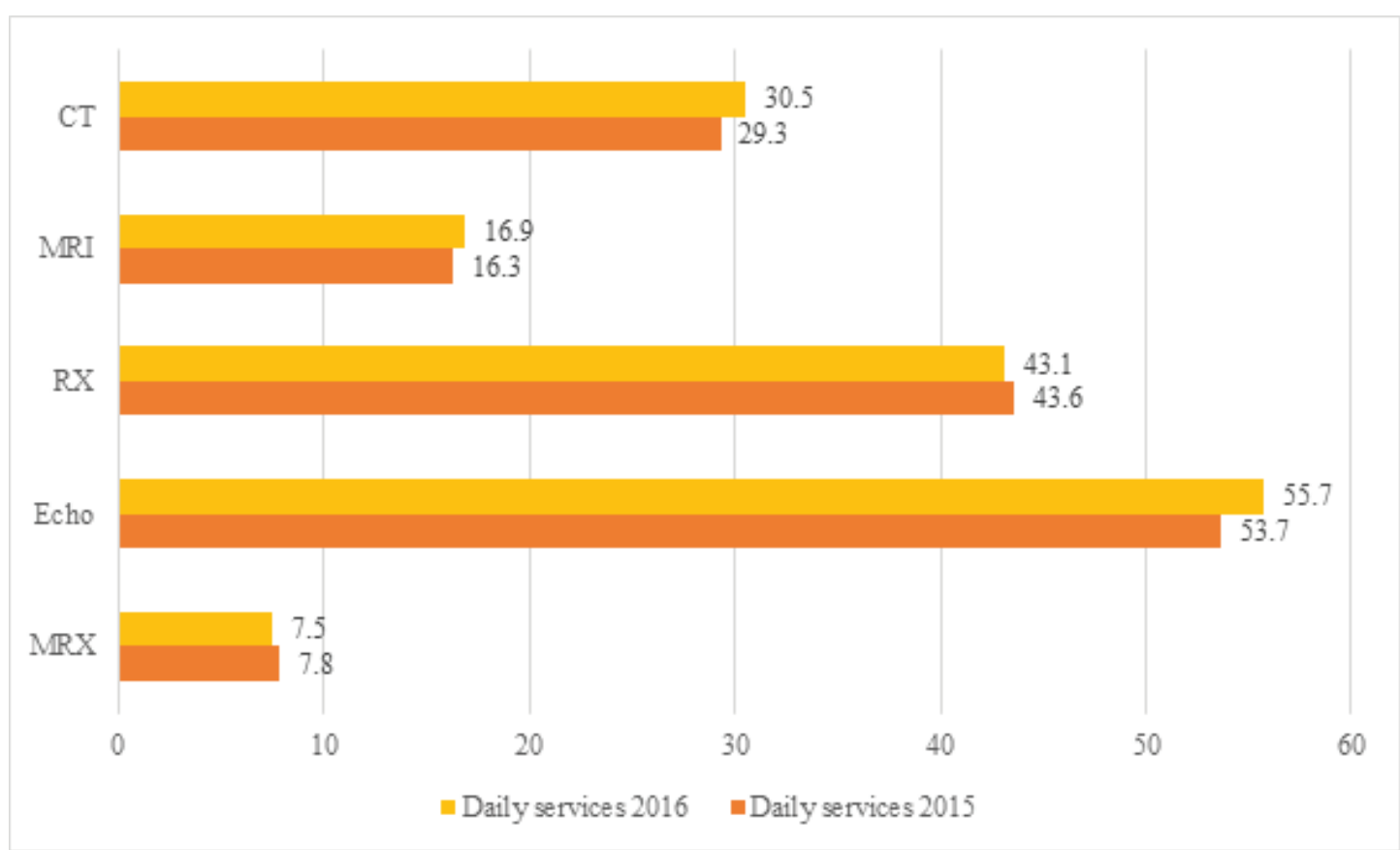

Figure 3: Daily services for each machine.

\section{The Standardized Investment Plan}

The study continues through the development of a more rational investment plan, called the "standardised investment plan". The standardised investment plan is able to realise strategic objectives and to allow the periodic renewal of the technologies, according to the standard of efficiency and in an adequately long period. It eliminates the many critical issues to create the conditions for the calculation of a hypothetical MES fee, which can be compared with the sustained costs.

The plan is articulated in ten years to manage the replacements of machinery, their degree of obsolescence and the automatic replacement of every machine, which reaches critical of optimal useful life for the Assobiomedica standard. The machinery prices and the technological level are considered stable over time by building the entire plan in 2016 with the absence of changes. These hypotheses are clearly the major constraint of the model, particularly if we consider the length of the period considered.

The represented plan is shown in table 1.

This plan must guarantee to cope both physical and technological obsolescence and to give the productive capacity to control the levels of inefficiency and ineffectiveness of the service, which are caused by the actual improper programming methodology. 
๙ุ

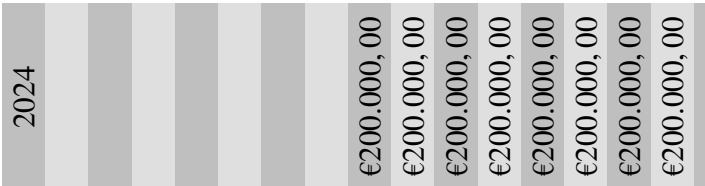

ฮิ่

\begin{tabular}{|c|c|c|}
\hline 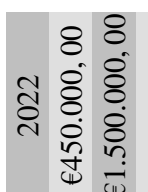 & 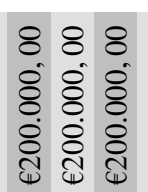 & 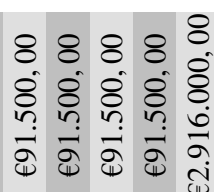 \\
\hline
\end{tabular}
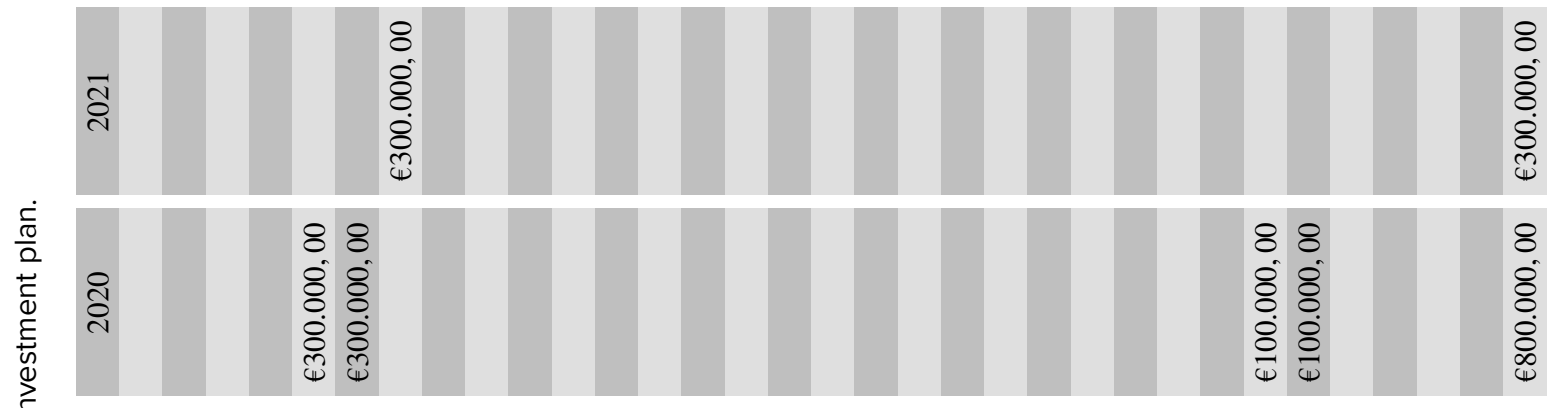

ลे

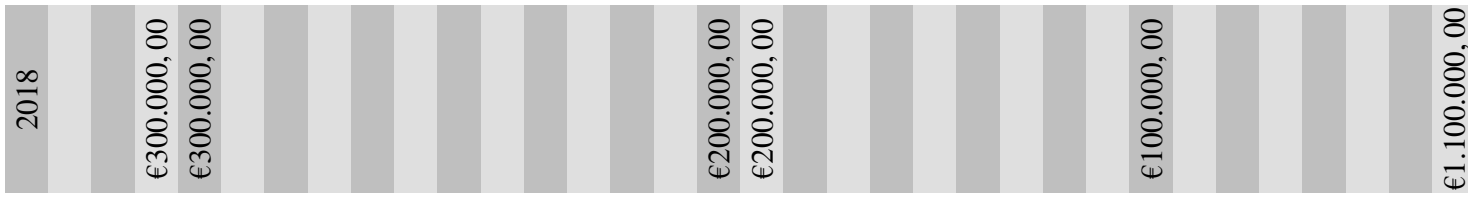

ิㅗำ
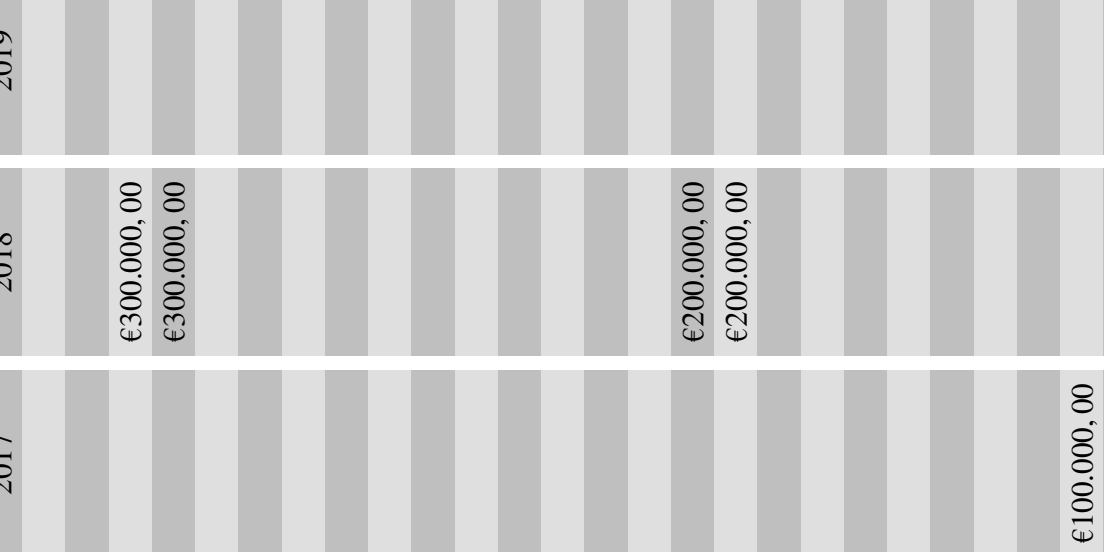

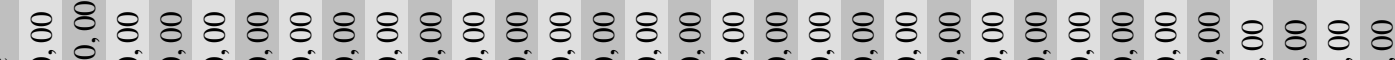

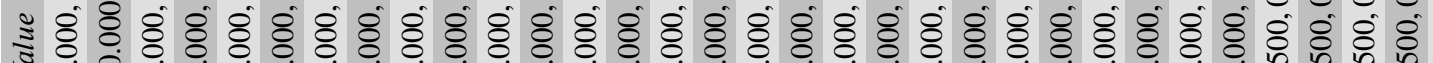

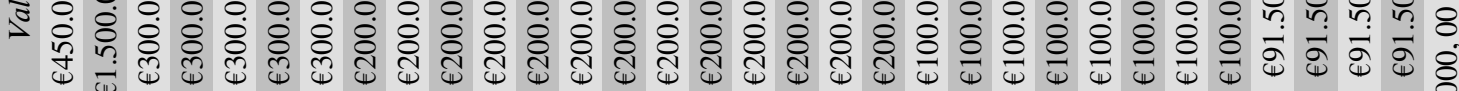

ิ \&

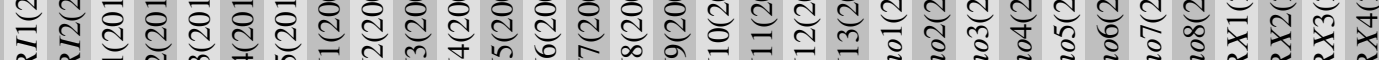

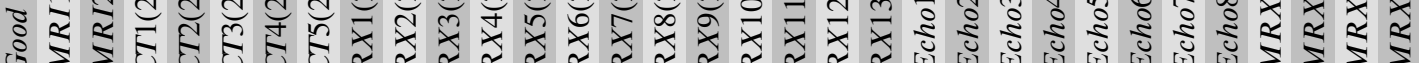


The standardised plan can allow the calculation of convenience between the application of MES and more traditional models, the classical three-year plan based on accounting logic instead of real investment needs.

The comparison of standardised plan with the Health Authority investments' plans 2016-2018 and 2017-2019 shows how the first is more efficient and more sustainable (fig. 4) because it allows a better linear planning and management of investments.

In particular, with the exception of 2016, in which the standardized model must recover the previous lack of investments, the overall expenditure always remains lower than the programmed one, concurrently guaranteeing a continuous renewal of the equipment.

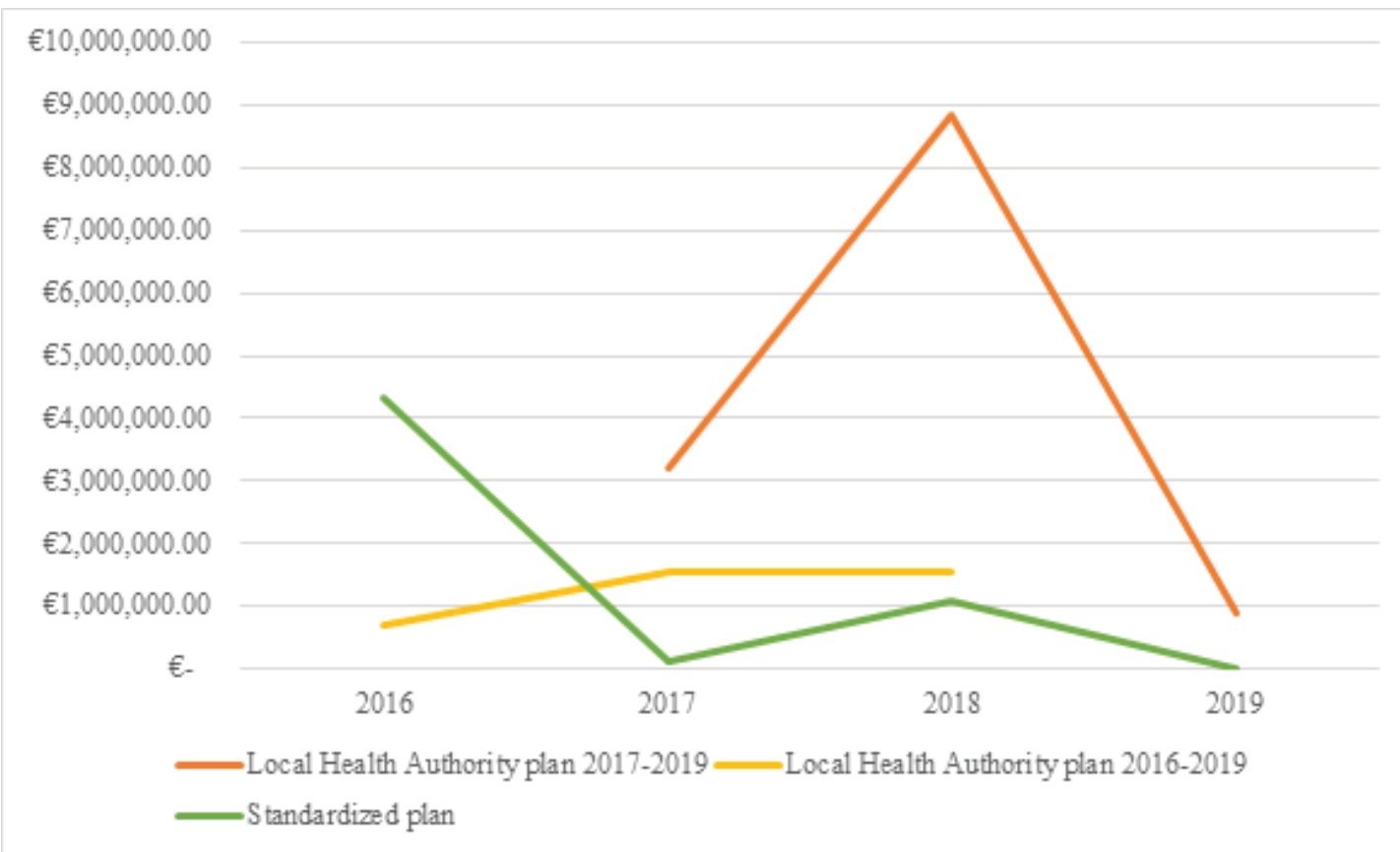

Figure 4: Comparison between Local Health Authority investments' plans and standardized plan.

\section{The Managed Equipment Service (MES) and the Analy- sis of the Potential Benefits}

Managed Equipment Service (MES) is a contract signed between an economic operator and a Local Health Authority or a Hospital for the supply of technologies characterised by the replacement of the traditional supply of goods with one of complex services. MES substitutes the traditional ownership with a complex contract for first supply, renewal, installation, testing, management, maintenance, updating, eventual disposal, performance monitoring and, sometimes, supply of consumables. The customer acquires the use of technologies and a range of support services offered by the supplier in partnership, against a periodic commensurate fee. 
To evaluate the convenience and potential benefits of MES, the standardised investment plan is used as a link between the traditional three-year plans and MES.

The fee MES is calculated applying more $10 \%$ on the cost of the value of new technological asset and an operation rate of more $6 \%$. This rate, reasonably recognisable in those used on the market, is both to discount the transaction flows and to calculate the rent. The annual MES fee is $€ 1,237,223.78$. It guarantees the scheduling of purchases, the automatic renewal of the equipment at the end of the expected life, the continuous routine maintenance of the entire installed park and the accessory consulting services.

In order to carry out a more precise analysis of convenience, the MES fee is compared with the disbursements arising from the traditional method investment plans and from the standardised plan (fig. 5).

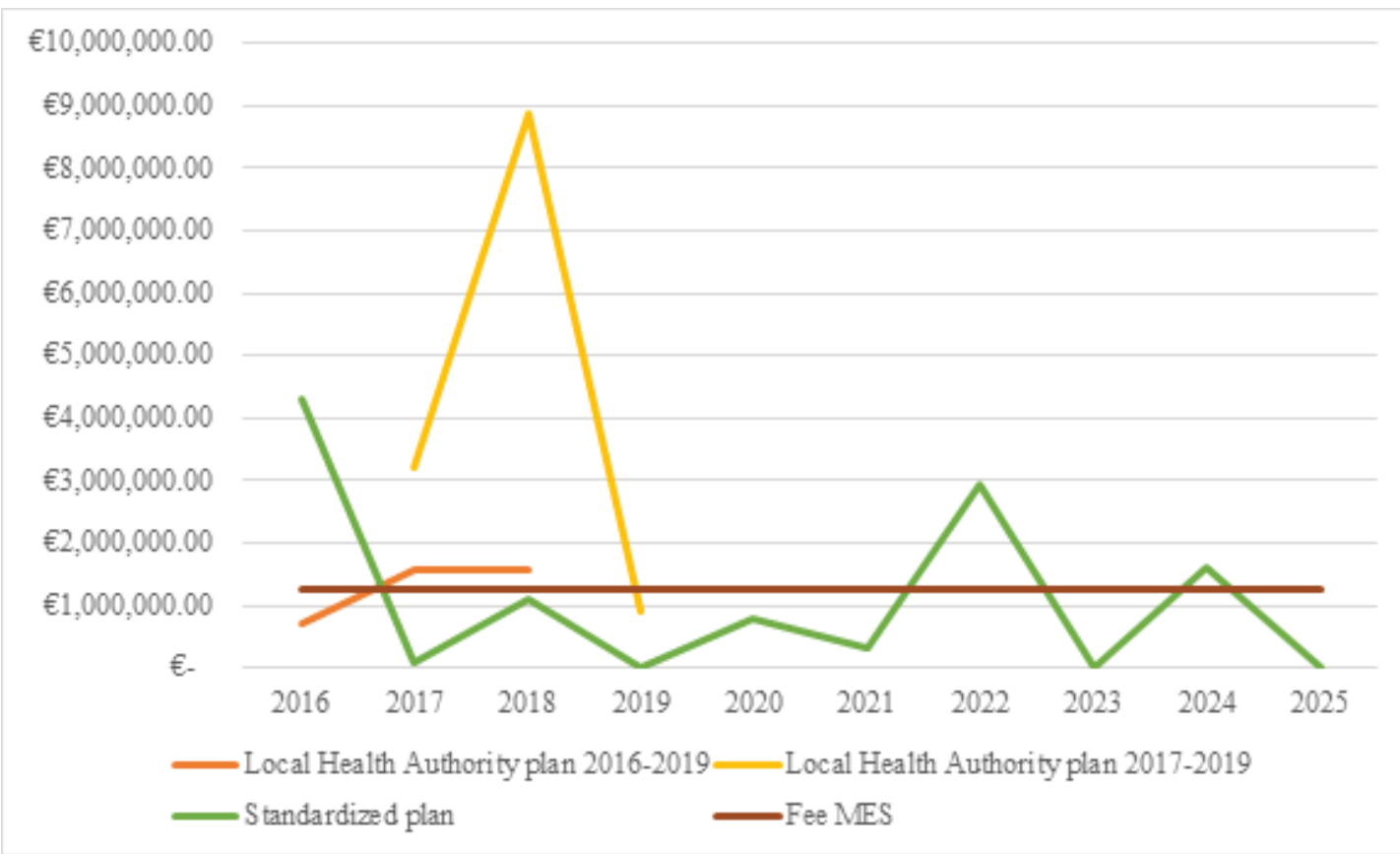

Figure 5: Disbursements relating to the MES fee, to the standardized plan and to the tradition investment plans of Health Authority (2016-2018 and 2017-2019).

MES appears reasonably sustainable and it is preferable for its financial advantage. The MES fee is continuously lower than the outlays required for the implementation of the technologies through direct purchase and it provides the possibility to enter the costs in the income statement rather than in the balance sheet.

The costs related to the investment plans realised to the Local Health Authority (20162018 and 2017-2019 disbursements), are compared in the period 2016-2019 with the standardised plan (elaborated in this study), the amount due in four years of the MES contract and with the supported depreciation of the analysed machinery by the hospital (fig. 6). 


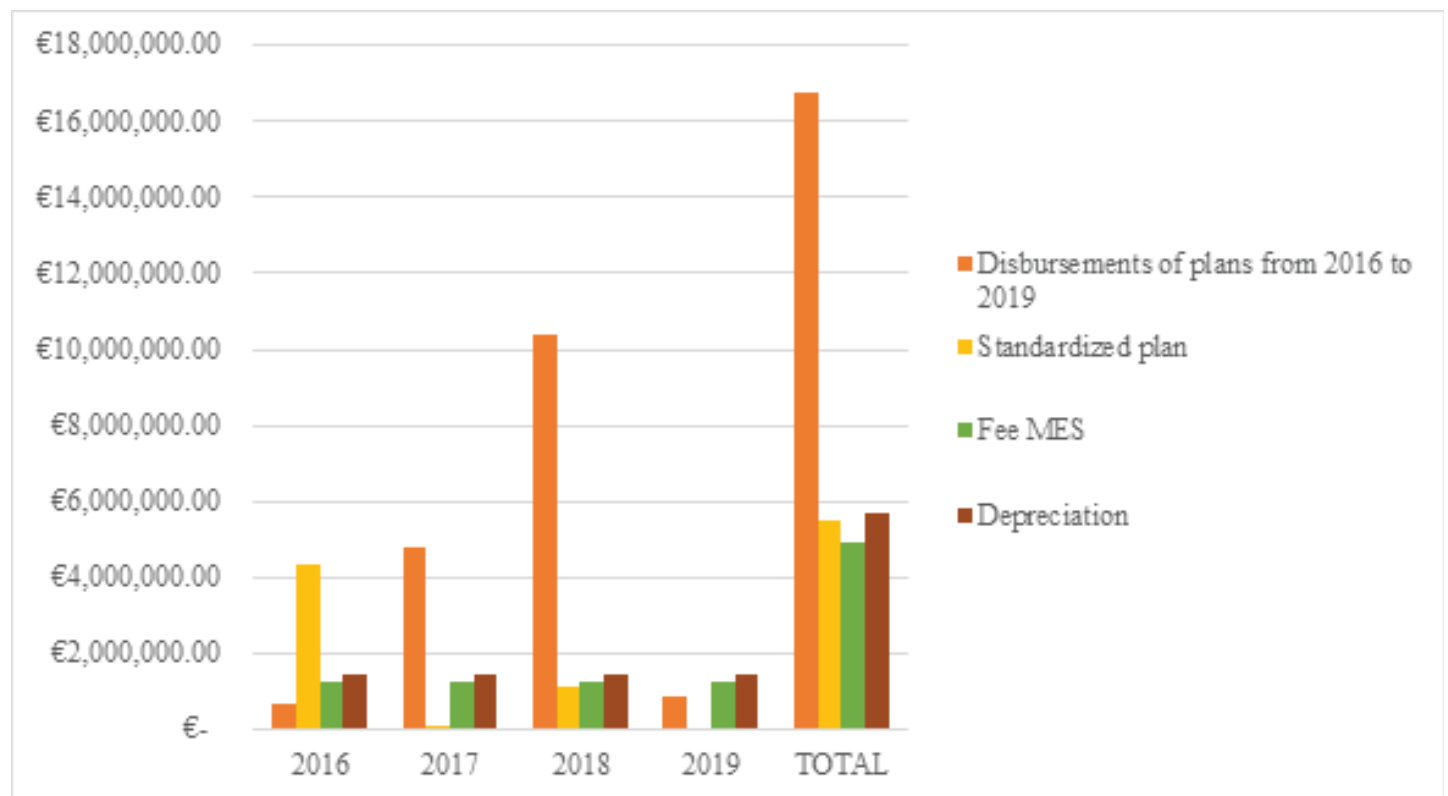

Figure 6: Effects on the income statement of the various programming tools.

The MES evidently is the most convenient option, which guarantees a more constant cost behaviour in addition to a higher performance of the technological equipment.

Although less significant than the analysis of financial convenience, the impact on the income statement of the various planning tools and the related investment acquisition methods is relevant for all the strategic directions. It gives the possibility to respect the constraints of the balance sheet.

\section{Conclusion}

The critical issues arising from the process of programming, acquisition and management of technologies is to find a solution with the implementation of the most modern Public-Private Partnership (PPP) systems, such as the Managed Equipment Service (MES).

The comparison between the found critical points in the traditional method of investment planning and the potential benefits of MES underlines the validity of this new contractual form. The MES fee (including maintenance charges and other ancillary services) is significantly lower than the expense incurred with the classical three-years investment plans used by the Italian hospitals and Local Health Authorities, as in the considered case study. 
The MES is consistently lower than the ordinary theoretical depreciation cost, which charges the balance sheet, and guarantees greater continuity in the investment; moreover, it offers the possibility to allocate its costs to the income statement, which is relevant given the absence of capital grants available.

If the total cost of the MES fee attributable to the four-year period (from 2016 to 2019) to the income statement is compared with the depreciation and budgeted disbursements in the investments' plans for the same period, the investment plan is $239 \%$ higher, the standardised plan $11 \%$ and, even that derived from the simple calculation of depreciation is $15 \%$ higher the MES fee.

Moreover, the replacement of costs in balance sheet for the depreciation equipment is less burdensome than the cost of MES fee, so constructed, and the last includes also the maintenance costs and a range of ancillary services available. Beyond the objective economic and financial advantages, a more correct distribution of managerial responsibilities and risks between the user and supplier, seen in this logic as a partner and not as its counterpart, appears as a winning step in the management of diagnostic technologies.

MES supports the sustainability of the health system offering the possibility to invest in technology although resources are limited and the regulatory constraints.

\section{References}

[1] Pontarollo E. (2000). "La gestione del parco tecnologico elettromedicale tra "outsourcing" e integrazione verticale", Issue 3 'Industry', July-September 2000, Webjournal "II Mulino";

[2] Cincotti F., V.Glorioso, Z. Guennouna, V. Tamborini (2014). "Il quadro economico e finanziario 2009-2018: dal Servizio Sanitario Nazionale alla Spesa Pubblica in dispositivi medici", N. 23, December 2014 for Centro Studi Assobiomedica (CSA) and Centro Europa Richerche (CER).

[3] Borgonovi E., P. Adinolfi, R. Palumbo, G. Piscopo (2018). "Framing the shades of sustainability in health care: pitfalls and perspectives from Western EU Countries", Journal Sustainability, 10, 4439;

[4] Mihaylova B., A. Briggs, A. O'Hagan, S. G. Thompson (2011). "Review of statical methods for analysing Healthcare Resouces and Costs" in Health Economics, 20, 897-916 (2011).

[5] Katz L., R. V. Fink, S. R. Bozeman, B. J. McNeil (2014). “Using Health Care Utilization and Publication Patterns to Characterized the research portfolio and to plan future 
research investments", PLoS ONE 9 (12);

[6] Andreoni A. (2017). "Strategies for emerging technologies and strategic sectors: evidence from OECD countries and some critical reflections on the Italian case", Issue 1 'Industry', January-March 2017, Webjournal "II Mulino";

[7] Giorgi C, I. Pavan (2018). ' Un sistema finito di fronte a una domanda infinita'. Le origini del Sistema sanitario nazionale italiano", Issue 2 'Paper and history', December 2018, Webjournal "II Mulino";

[8] McKee M., N. Edwards, R. Atun (2006). "Public-private partnerships for hospitals", Bulletin of the World Health Organization, November 2006, 84 (11);

[9] Tekin P. S. (2012). "Public-private partnership and the healthcare sector," Turkish Review 2, no. 4 (2012): 48-55;

[10] Hoppe E. I., P. W. Schmitz (2013). "Public-private partnerships versus traditional procurement: Innovation;

[11] Bizzotto G., V. Codazzi (2016). "Produzione, ricerca e innovazione nel settore dei dispositivi medici in Italia. Rapporto 2016." By Centro Studi Assobiomedica in collabortion with Centro Europa Richerche (CER);

[12] Egan P. (2018). "Managed equipment service -- Is it all it's cracked up to be?", European journal of medical physics, Volume 52, 165;

[13] Eisenhardt K. M. (1989). "Building theories from case study research." Academy of Management Review, October, 14 (4), 532-550;

[14] Yin R. (1994). "Case study research: Design and methods (2nd ed.)." Thousand Oaks: Sage Publishing.

[15] Parri E. (2015). "The installed machinery of diagnostic imaging equipment in Italy: the state of the art between adequacy, obsolescence and innovation with a view to sustainability of the system", $N^{\circ} 32$ of Assobiomedica Study;

[16] COCIR REPORT (2016). "Indicators targeting EU heathcare sustainability goals";

[17] Progress Consulting S.r.l. and Living Prospects Ltd (2012). “La gestione dei sistemi sanitari negli Stati membri dell'UE. II ruolo degli enti locali.". 